\title{
PHYLOGENETIC ANALYSIS OF CHLOROPLAST DNA RESTRICTION SITE DATA AT HIGHER TAXONOMIC LEVELS: AN EXAMPLE FROM THE ASTERACEAE
}

\author{
Robert K. Jansen, ${ }^{1}$ Kent E. Holsinger, ${ }^{1}$ Helen J. Michaels, ${ }^{2,3}$ and Jefrrey D. Palmer ${ }^{2,4}$ \\ ${ }^{\prime}$ Department of Ecology and Evolutionary Biology, University of Connecticut, Box $U-42$, \\ Storrs, CT 06269 USA \\ ${ }^{2}$ Department of Biology, University of Michigan, Ann Arbor, MI 48109 USA
}

\begin{abstract}
Chloroplast DNA variation was examined among 57 genera of Asteraceae representing 15 currently recognized tribes. Complete cleavage maps were constructed for 11 six-base pair restriction enzymes, and a total of 927 cleavage site differences was detected, 328 of which are phylogenetically informative. The data were used to construct phylogenetic trees using both Wagner and Dollo parsimony and the resulting monophyletic groups were evaluated statistically using the bootstrap method. The level of homoplasy in the restriction site data is $54-56 \%$ (excluding autapomorphies), most of which is due to parallel site losses. The most parsimonious trees generated by both parsimony methods have nearly identical topologies at lower taxonomic levels, but differ in subfamilial circumscriptions and tribal groupings. Dollo parsimony provides support for the monophyly of two subfamilies, the Lactucoideae (excluding the Barnadesiinae) and Asteroideae, but Wagner parsimony supports the monophyly of the Asteroideae only. This incongruence is due to different assumptions of the two parsimony methods about relative rates of parallel site gains and losses. After eliminating the six most rapidly changing restriction sites or performing successive approximation, Wagner parsimony produces trees with the same subfamilial groupings as the Dollo trees. We conclude that the Dollo tree with two monophyletic subfamilies is the best estimate of phylogenetic relationships in the Asteraceae because this method more accurately reflects the evolution of restriction sites. We also demonstrate that in spite of high levels of homoplasy in chloroplast DNA restriction site data at these higher taxonomic levels, it is possible to make statistically supported estimates of phylogenetic relationships.
\end{abstract}

Received September 19, 1989. Accepted April 9, 1990.

Recently there has been a rapid surge in the use of comparative restriction site mapping of the chloroplast genome for phylogeny reconstruction (reviewed in Palmer, 1987; Palmer et al., 1988). Most studies have used this approach to examine relationships among closely related species or genera of flowering plants. These studies demonstrate low levels of homoplasy $(0-5 \%)$ in chloroplast DNA (cpDNA) restriction site data, enabling the construction of consistent and statistically supported phylogenies at low taxonomic levels. For many of the previous investigations the phylogenetic analysis of restriction site data was simple, with good congruence among the trees generated by different algorithms. The use of cpDNA restriction site data at higher taxonomic levels will naturally result in increased levels of

\footnotetext{
${ }^{3}$ Current address: Department of Biology, Bowling Green State University, Bowling Green, OH 43402 USA.

${ }^{4}$ Current address: Department of Biology, Indiana University, Bloomington, IN 47405 USA.
}

convergent and parallel mutations, making phylogenetic analyses more complicated. Several theoretical studies proposed alternative phylogenetic methods for dealing with homoplasious changes (Templeton, 1983a, 1983b, 1987; DeBry and Slade, 1985; Nei and Tajima, 1985, 1987; Li, 1986). Only a few investigations of $\mathrm{cpDNA}$ restriction site variation have compared the efficacy of the different algorithms (Sytsma and Schaal, 1985; Sytsma and Gottlieb, 1986; Jansen and Palmer, 1988; Schilling and Jansen, 1989), but in all of these studies the level of homoplasy was sufficiently low that nearly identical results were obtained for all methods.

We are examining cpDNA variation in the sunflower family (Asteraceae) to provide new characters for evaluating phylogenetic relationships at higher taxonomic levels. In this paper we compare trees generated by several different methods of phylogenetic analysis using a large number of $\operatorname{taxa}(57)$ and restriction site mutations (328). Our results demonstrate that different trees 
are generated by Dollo and Wagner parsimony methods. However, theoretical considerations, a posteriori character weighting, and statistical analyses all favor the Dollo tree with two monophyletic subfamilies of Asteraceae, Lactucoideae (excluding the Barnadesiinae) and Asteroideae. A detailed discussion of the systematic and evolutionary implications of the cpDNA variation in the Asteraceae is provided in a separate paper (Jansen et al., 1991).

\section{Materials AND Methods}

Because there are over 1,100 genera in the Asteraceae it was necessary to sample representative taxa for our examination of restriction site variation. We selected 57 genera (Table 1) from 15 of the currently recognized tribes. Within each tribe we selected a single species from each of three to eight genera representing diverse evolutionary lineages. Five additional genera (Blennosperma, Cotula, Echinops, Stokesia, and Ursinia) whose assignment to particular tribes has been controversial were also included in the analysis.

Chloroplast DNAs were isolated using the sucrose gradient technique of Palmer (1986). Where tissue amounts were limited, total DNA was extracted by the procedure of Saghai-Maroof et al. (1984) and further purified in cesium chloride/ethidium bromide gradients. Restriction endonuclease digestions, agarose gel electrophoresis, bidirectional transfer of DNA fragments to Zetabind (AMF CUNO) nylon filters, labelling of recombinant plasmids by nick-translation, filter hybridizations, and autoradiography were performed as described in Palmer (1986), Jansen and Palmer (1987a), and Palmer et al. (1988). A total of 22 cloned restriction fragments of lettuce cpDNA (see Fig. 1 in Jansen and Palmer, 1988) were used in filter hybridization experiments to map sites for 11 enzymes (Appendix I) in cpDNAs of all 57 examined species. The mapping strategy involved a simplification of the overlap hybridization procedure (Palmer, 1986; Jansen and Palmer, 1987a) as described in Jansen and Palmer (1988).

Restriction site data were analyzed by both Wagner (Farris, 1970) and Dollo (LeQuesne, 1974) parsimony on MacIntosh and Zenith microcomputers and an IBM 3090 using PAUP (Phylogenetic Analysis Using Parsimony; developed by D. Swofford, version 3.0), PHYLIP (Phylogenetic Inference Package; developed by J. Felsenstein, version 3.2) and HENNIG86 (developed by S. Farris, version 1.5). Global branch swapping with MULPARS (Hold=5) and the mhennig* $b^{*}$ options were performed to search for the most parsimonious tree using PAUP and HENNIG86, respectively. Wagner parsimony gives equal weight to parallel restriction site gains and losses, whereas Dollo parsimony prohibits parallel site gains but allows parallel site losses. A discussion of the limitation of both parsimony algorithms is provided in DeBry and Slade (1985) and Jansen and Palmer (1988). The CONTREE and NELSEN options of PAUP and HENNIG86 were used to generate a strict consensus tree when more than one equally parsimonious tree was found. $\mathrm{Re}-$ peated successive approximations (Farris, 1969; Carpenter, 1988) were performed on the most parsimonious Wagner trees using the $x s$ w cc options in HENNIG86. The bootstrap method (Felsenstein, 1985, 1988) of PHYLIP was used to place confidence intervals on monophyletic groups. The large data matrix (57 taxa and 328 mutations) required the use of an IBM 3090 computer at the University of Connecticut Computer Center. One hundred bootstrap replicates were performed, and majority rule consensus trees were constructed using Wagner and Dollo parsimony and the local branch swapping option. A modification of the bootstrap algorithm permitted the examination of all 100 replicate trees.

All trees were rooted using the subtribe Barnadesiinae of the tribe Mutisieae as the outgroup. Our previous cpDNA studies in the Asteraceae identified this subtribe as the sister group to the rest of the family. This placement of the Barnadesiinae is strongly supported by its primitive chloroplast genome arrangement (Jansen and Palmer, $1987 a, 1987 b)$ and by phylogenetic analyses of restriction site data (Jansen and Palmer, 1988) and sequence data (Michaels, Palmer, and Jansen, unpubl.) using other Asteridae families as outgroups. Furthermore, a recent cladistic study of the Asteraceae based primarily on morphological data (Bremer, 1987), but also including the $22 \mathrm{~kb} \mathrm{cpDNA}$ 


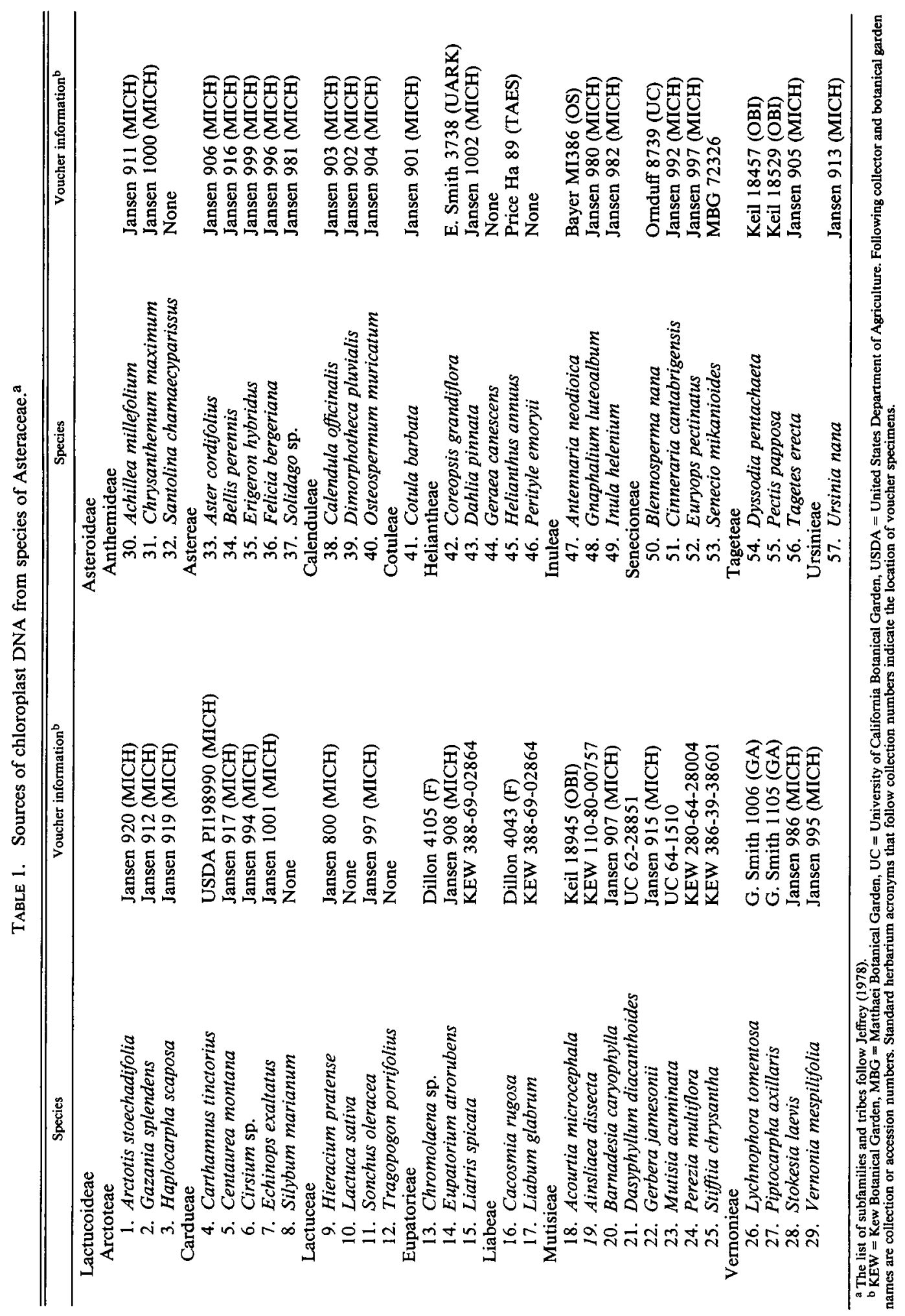


inversion (Jansen and Palmer, 1987b), placed the Barnadesiinae at a basal position in the Asteraceae. We selected one species (Table 1) from two of the seven genera of this subtribe (sensu Cabrera, 1977) to root the phylogenetic trees.

\section{RESULTS}

\section{Restriction Fragment Length Variation}

The size of the chloroplast genome in the 57 genera of Asteraceae examined here ranges from 148 to 151 kilobases. One hundred and fifty one restriction fragment length variations ranging in size from 100 to 800 base pairs (bp) were detected. The majority (108) of the length variants were less than $200 \mathrm{bp}$. This number represents a lower bound on length variation because we could not detect deletions and insertions smaller than $100 \mathrm{bp}$ in our gel system. Palmer (1985) has previously noted that most length mutations in cpDNA are $1-10 \mathrm{bp}$ in size. Jansen and Palmer (1988) provide details on the frequency of length variation within the major regions of the chloroplast genome (inverted repeat and small and large single copy regions).

Length mutations are not generally used in the phylogenetic analyses because of the difficulty associated with determining homology (see discussion in Moritz et al., 1987; Palmer et al., 1988). We determined the extent and location of length variation to distinguish between restriction fragment changes caused by base substitutions and those caused by length mutations. We included in the analysis a single $300 \mathrm{bp}$ length mutation (character number 5 in Appendix I). This length mutation occurs in only two discrete and readily distinguished size classes, is unambiguously polarized, and maps to the same location in the inverted repeat, where little length variation has been found (Jansen and Palmer, 1988; Schilling and Jansen, 1989; Wallace and Jansen, 1990). Thus, it is likely to be homologous in those taxa that share it.

\section{Phylogenetic Analysis of Restriction Site Mutations}

Approximately 400 restriction sites were mapped in cpDNAs of each of the 57 species examined in the Asteraceae. A total of 927 site changes was detected, 328 of which are phylogenetically informative (Appendix I). The Wagner parsimony analysis resulted in 20 equally parsimonious trees of 1,316 steps (including autapomorphies) and with a consistency index of 0.46 (excluding autapomorphies). If autapomorphies are included the consistency index is 0.70 . Inferred homoplasious site changes include 262 parallel losses, 11 parallel gains, 55 gain/losses, and 60 loss/gains. One of the shortest trees is shown in Figure 1 and a strict consensus tree of the 20 equally parsimonious trees is shown in Figure 2 (reduced to show only tribes).

The Wagner trees (Figs. 1, 2) support the monophyly of 13 previously recognized tribes in the Asteraceae, including the $\mathrm{Mu}-$ tisieae (excluding the subtribe Barnadesiinae), Cardueae, Lactuceae, Liabeae, Vernonieae, Arctoteae, Astereae, Calenduleae, Anthemideae, Senecioneae, Inuleae, Coreopsideae and Eupatorieae. The tribes $\mathrm{He}-$ liantheae and Tageteae are shown to be paraphyletic. The positions of Coreopsis and Dahlia support their separation as a trite distinct from the core of the Heliantheap. A number of genera that had been previously segregated as distinct tribes or whose tribal affinities were uncertain are grouped with one of the monophyletic tribes (Fig. 1), including Ursinia (Anthemideae), Cotula (Anthemideae), Echinops (Cardueae), Stokesia (Vernonieae) and Blennosperma (Senecioneae). Thus, the tribal placement of these genera is resolved by the cpDNA data.

The Wagner trees provide insights into phylogenetic relationships among the tribes (Figs. 1, 2). The subfamily Asteroideae is monophyletic in all 20 trees and includes the nine tribes Astereae, Calenduleae, Anthemideae, Senecioneae, Inuleae, Coreopsideae, Eupatorieae, Heliantheae, and Tageteae. The second previously recognized subfamily, Lactucoideae (excluding the Barnadesiinae, sensu Carlquist, 1976 or Wagenitz, 1976), is monophyletic in 8 and paraphyletic in 12 of the 20 most parsimonious trees, and therefore collapses in the strict consensus tree (Fig. 2). The Vernonieae and Liabeae form a monophyletic group in all equally parsimonious trees, but no other tribal groupings occur within the paraphyletic Lactucoideae. Within the Asteroideae 


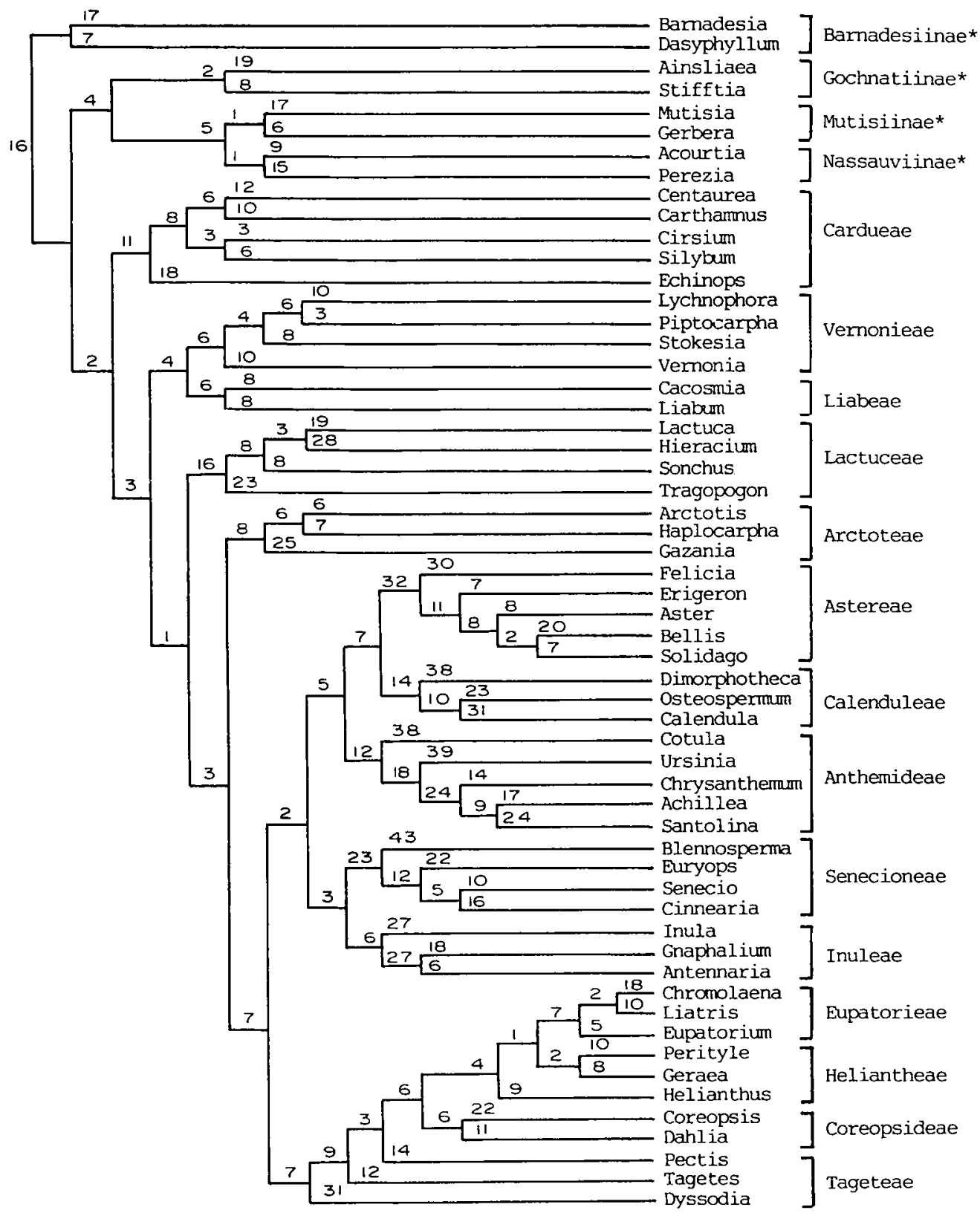

FIG. 1. One of 20 equally most parsimonious Wagner trees using 927 restriction site mutations, 328 (Appendix I) of which are phylogenetically informative. The tree has a total of 1,316 steps (including autapomorphies) and a consistency index of 0.46 (without autapomorphies) or 0.70 (with autapomorphies). Brackets show the current circumscription of 15 tribes, while the four subtribes of the Mutisieae (sensu Cabrera, 1977) are indicated with asterisks. The numbers at each node and along each lineage indicate the number of site mutations.

two major groups of tribes are present in all 20 trees. The first includes the Astereae and Calenduleae, and the second includes the Eupatorieae, Heliantheae, Coreopsideae, and Tageteae.
The Dollo parsimony analysis resulted in 16 equally parsimonious trees with a length of 1,344 steps (28 steps longer than the shortest Wagner trees, including autapomorphies). The trees have a consistency in- 

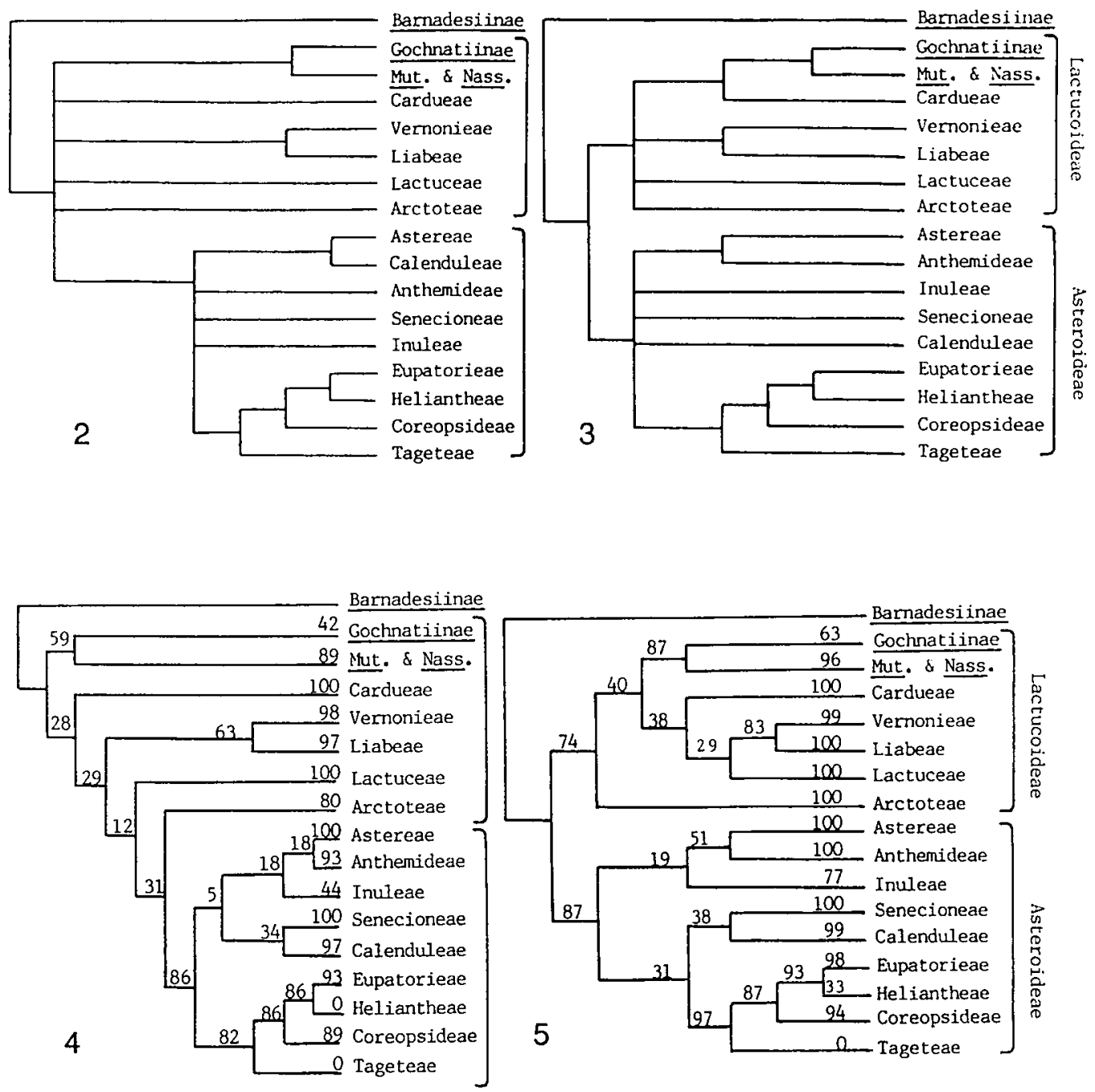

Figs. 2, 3. Strict consensus Wagner (Fig. 2) and Dollo (Fig. 3) trees using 927 cpDNA restriction site mutations, 328 (Appendix I) of which were phylogenetically informative. The trees have been reduced to show the tribes only except for the four subtribes of the Mutisieae (underlined). Brackets show circumscription of subfamilies of Asteraceae according to Thorne (1983). The Wagner tree has a total of 1,316 steps (including autapomorphies) and a consistency index of 0.46 (without autapomorphies) or 0.70 (with autapomorphies) and the Dollo has 1,344 steps and a consistency index of 0.44 (without autapomorphies) or 0.69 (with autapomorphies).

FIGS. 4, 5. Majority-rule consensus trees generated by the bootstrap analysis using $927 \mathrm{cpDNA}$ restriction site mutations (328 informative ones) using Wagner (Fig. 3) and Dollo (Fig. 4) parsimony. The trees have been reduced to show the tribes of Asteraceae only except for the four subtribes of the Mutisieae (underlined). Numbers indicate how many times out of 100 bootstrap replicates that a monophyletic group occurred. Brackets show the circumscription of subfamilies according to Thorne (1983).

dex of 0.44 without autapomorphies, or 0.69 if autapomorphies are included. Since Dollo parsimony prohibits parallel gains and losses/gains, all homoplasious changes are necessarily parallel losses or gain/losses. The CONTREE option of PAUP generated a strict consensus tree of the 16 equally parsimonious trees (Fig. 3). The tree has been reduced in size to show only the tribes of Asteraceae since the generic groupings were identical to those in the Wagner strict consensus tree (Figs. 1, 2) with the following 
four minor exceptions. In the Dollo tree, 1) Lactuca and Sonchus are sister taxa; 2) the three genera of the Eupatorieae form an unresolved trichotomy; 3) Helianthus is included in a monophyletic group with Perityle and Geraea; and 4) Pectis and Tagetes form a monophyletic group.

The Dollo tree (Fig. 3) provides a different scheme of tribal relationships in the Asteraceae than the Wagner trees. The most notable difference is that four restriction site changes (characters 9, 143, 192, 199 in Appendix I), three of which are parallel losses, support the monophyly of the subfamily Lactucoideae (excluding the Barnadesiinae). A re-evaluation of these four characters reveals that the polarity of number 192 is somewhat uncertain because of variation within the two outgroup genera of the Barnadesiinae for this restriction site. Our polarity decision was based on the absence of this site in mapped cpDNAs from related Asteridae families, including the Rubiaceae and Dipsacaceae. If the polarity of this site is reversed, Dollo parsimony produces 14 equally parsimonious trees of 1,345 steps, none of which support the monophyly of the Lactucoideae. However, in Dollo trees only one step longer the lactucoid tribes do form a monophyletic group. Two additional differences between the Dollo and Wagner trees are (compare Figs. 2, 3): 1) in the Dollo tree the Cardueae and those Mutisieae with the cpDNA inversion (Jansen and Palmer, $1987 b$ ) form a monophyletic group; and 2) the Astereae is the sister tribe to the Anthemideae rather than the Calenduleae. Similarities between the Wagner and Dollo analyses include support for the monophyly of 13 of the 15 previously recognized tribes of Asteraceae and the subfamily Asteroideae, the close phylogenetic relationship of the Liabeae and Vernonieae, and the inclusion of the Tageteae, Coreopsideae, Heliantheae, and Eupatorieae in a monophyletic group.

The bootstrap resampling method (Felsenstein, 1985, 1988) determined the reliability of our phylogenetic conclusions. One hundred replicate samples were performed using Wagner and Dollo parsimony, and majority-rule consensus trees were constructed (Figs. 4, 5, reduced to show only the tribes; see Figs. 1 and 2 in Jansen et al., 1991 for trees including all taxa). The total lengths of these trees were 1,319 and 1,345 steps for the Wagner and Dollo analyses, respectively. The number of times each monophyletic group occurred in the 100 replicates is given on the trees. Felsenstein (1985) considered a 95\% frequency of occurrence as evidence of statistical significance. However, the bootstrap analysis gives a conservative estimate of the composition of any particular group in that all taxa and only those taxa must be included in that group to be recorded from any of the 100 replicate trees (see Sanderson, 1989 for detailed discussion). Thus, although several groups do not occur in more than $95 \%$ of the bootstrap replicates, we believe that these groups should be viewed as being supported by the data.

There is strong statistical support (Figs. $4,5)$ for the monophyly of most of the 13 tribes that were monophyletic in the Wagner and Dollo trees, including the Mutisieae (excluding the subtribe Barnadesiinae; $59 \%$ Wagner and $87 \%$ Dollo), Cardueae (100\% both), Vernonieae ( $98 \%$ and $99 \%)$, Liabeae (97\% and $100 \%)$, Lactuceae (100\%), Arctoteae $(80 \%$ and $100 \%)$, Astereae $(100 \%)$, Anthemideae (93\% and $100 \%$ ), Senecioneae $(100 \%)$, Calenduleae $(97 \%$ and $99 \%)$, Coreopsideae (89\% and 94\%), and Eupatorieae (93\% and $98 \%)$. Only the Inuleae, which was monophyletic in $40 \%$ (Wagner, Fig. 4) or $77 \%$ (Dollo, Fig. 5) of the bootstrap replicates is not strongly supported statistically. Inspection of the 100 trees in the bootstrap sample reveals that the low confidence interval of this tribe can be attributed to the grouping of Inula with other tribes, especially the Astereae, Senecioneae, Anthemideae, or with the monophyletic group including the tribes Tageteae, Heliantheae, and Eupatorieae. Both bootstrap analyses support the monophyly of the subfamily Asteroideae ( $86 \%$ and $87 \%$ ), which was shown to be monophyletic in all of the equally parsimonious trees generated by Wagner and Dollo parsimony (Figs. 1-3). The group of tribes comprising the subfamily Lactucoideae (excluding the Barnadesiinae) occurs in only 29 of the 100 bootstrap replicates in the Wagner analysis and does not appear in the majority-rule consensus tree. In contrast, the Dollo analysis provides moderate statistical support for the monophyly of the 
Lactucoideae (74\%). Overall, the bootstrap confidence intervals are consistently higher in the Dollo tree (Fig. 5) than in the Wagner tree (Fig. 4).

There is a high level of homoplasy in the cpDNA data, as well as substantial differences between the Wagner and Dollo trees concerning the monophyly of the Lactucoideae and the relationships among the tribes of Asteraceae. However, note that in the Wagner tree $186(57 \%)$ of the 328 phylogenetically informative restriction sites change only once and most of the homoplasy in the data set is due to a small proportion of the sites changing multiple times (Fig. 6). Furthermore, 166 of the 186 sites that change only once are restriction site gains, whereas most of the changes at the frequently changing sites are homoplasious losses. This is not surprising in view of the much higher probability of parallel site losses than gains (Templeton, 1983a, 1983b; DeBry and Slade, 1985). To determine if elimination of the more rapidly evolving sites would resolve some of the differences between the Dollo and Wagner trees, we developed a conservative statistical test for outliers based on the average number of changes in the data set (see Appendix II). With $95 \%$ confidence, all characters that change nine times or more are outliers and can be deleted. Six characters (numbers 146 , 147, 164, 209, 213, and 326 in Appendix I) were removed and the remaining $322 \mathrm{mu}$ tations were reanalyzed using Wagner parsimony and bootstrapping (trees not shown).

The Wagner analysis of the reduced data set resulted in a single most parsimonious tree with a length of 1,252 (including autapomorphies). The tree has a consistency index of 0.49 without autapomorphies and 0.74 if autapomorphies are included. Although only six characters have been deleted, the tree is 64 steps shorter than the Wagner tree generated using the complete data set. The Wagner tree using 322 mutations provides support for the monophyly of both the subfamilies Asteroideae and Lactucoideae, which agrees with the relationships indicated by the Dollo trees (Figs. 3, 5) for the complete data set. In this case, however, there are only two (versus four for Dollo) site changes (numbers 192 and 199 in Appendix I) supporting the monophyly of the

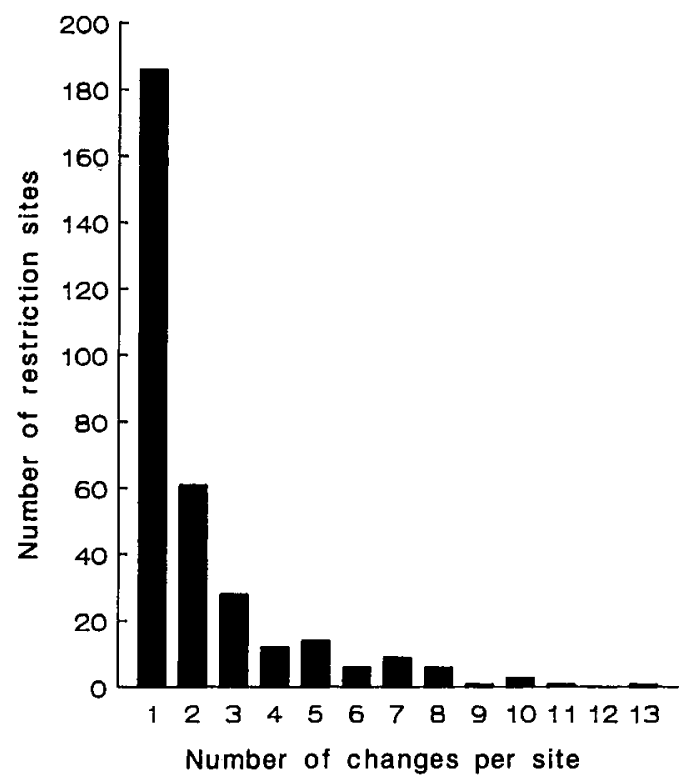

FIG. 6. Histogram showing the number of changes for the 328 informative restriction sites based on the Wagner majority-rule consensus tree.

Lactucoideae (excluding the Barnadesiinae) and the only one of these that is not homoplasious (number 192) is of uncertain polarity (see above). The Lactucoideae occurs in only 28 of the 100 bootstrap replicates in the reduced data set, again providing only weak statistical support for the monophyly of this subfamily with Wagner parsimony.

Successive approximation (Farris, 1969; Carpenter, 1988) is another approach for reducing the influence of the rapidly evolving restriction sites on the phylogenetic estimates using Wagner parsimony. This is an a posteriori weighting method that alters the weight of characters on the basis of how many times they change in the equally parsimonious trees. Characters that change more than once are down weighted by the average number of times they change on the shortest trees. Parsimony analysis is performed on a data set using new weights, and this is repeated until the cladograms on successive iterations are identical. After four rounds of successive approximation using the Asteraceae restriction site data set, 20 trees were generated with a consistency index of 0.88 (excluding autapomorphies). All trees (not shown) support the monophyly of the two subfamilies Lactucoideae (exclud- 
ing the Barnadesiinae) and Asteroideae, a topology that is congruent with the Dollo trees (Figs. 3, 5).

\section{Discussion}

Dollo and Wagner parsimony analyses of cpDNA restriction site data in the Asteraceae generate phylogenetic trees that differ in the circumscription of subfamilies and tribal relationships. These differences have major implications for our understanding of the systematics of this large and important flowering plant family. The most notable difference is that the Dollo trees support the monophyly of two subfamilies, Asteroideae and Lactucoideae (excluding the Barnadesiinae), whereas most of the equally parsimonious and the majority-rule Wagner trees support the monophyly of the former tribe only. This incongruence is due to the different assumptions about relative rates of parallel site gains and losses in these two parsimony methods. Templeton (1983a, $1983 b$ ) indicated that there are four major types of parallel changes in restriction sites: 1) loss/gain, 2) parallel gain, 3) parallel loss, and 4) gain/loss. For a six base pair restriction enzyme there are 18 different ways to lose a site, but only one way to gain a site if the recognition sequence is only one substitution away from being a recognition site. Thus, Templeton's type three and four parallel changes occur at least an order of magnitude more frequently than type one and two. In fact, in comparisons involving very divergent taxa, parallel losses may be more than 30 times as frequent as parallel gains (Templeton, 1983b).

Wagner parsimony assumes that parallel site gains and losses are equally likely, whereas Dollo parsimony assumes that the probability of a parallel site loss is much greater than a parallel gain, and in fact prohibits this latter class of mutations. DeBry and Slade (1985) provided statistical arguments that Dollo parsimony is a more consistent and efficient estimator of phylogenetic relationships from restriction site data because it takes into account the differential probability of parallel site gains and losses. Their conclusion was based on animal mitochondrial DNA, but they suggested that Dollo parsimony would be the method of choice for restriction site data for other ge- nomes as well. Although complete prohibition of parallel gains may be unrealistic especially in comparisons among divergent taxa (Jansen and Palmer, 1988), it is clearly closer to the truth that parallel gains are much less likely than parallel losses. Thus, the Dollo trees probably represent a better estimate of phylogenetic relationships within the Asteraceae than the Wagner trees.

Wagner analyses also provide some support for the monophyly of the subfamily Lactucoideae (excluding the Barnadesiinae) since eight of twenty equally parsimonious trees support its monophyly. Furthermore, a posteriori character weighting by successive approximation (Farris, 1969; Carpenter, 1988) and by elimination of the most rapidly changing restriction sites produces Wagner trees that have the Lactucoideae as a monophyletic group. Finally, we note the moderately high confidence interval (74\%, Fig. 5) of the Lactucoideae in the Dollo bootstrap analysis. Thus, we conclude that our combined Wagner and Dollo analyses provide substantial, although by no means overwhelming, support for the monophyly of the two subfamilies Asteroideae and Lactucoideae.

The bootstrap confidence intervals are consistently higher in the Dollo majorityrule consensus tree (Fig. 5) than the Wagner tree (Fig. 4). This is due primarily to the greater likelihood that a group sharing site gains will appear in each of the 100 Dollo bootstrap replicates. Numerous examples support this explanation (compare Figs. 1 and 2 in Jansen et al., 1991). For example, the monophyletic group including the tribes Liabeae and Vernonieae shares the same two restriction site gains in both the Dollo and Wagner trees, but the confidence interval for this group is $20 \%$ higher in the Dollo analysis. This pattern was not observed in the two previous bootstrap comparisons of these parsimony methods (Jansen and Palmer, 1988; Schilling and Jansen, 1989); however, in both of these studies homoplasy was lower (30-40\% vs. $54-56 \%$ here, excluding autapomorphies).

We have made two methodological observations that will be pertinent for the future use of restriction site data at higher taxonomic levels. First, it is important to analyze the data using a diverse array of 
phylogenetic methods, especially ones that identify the statistical strengths and weaknesses of monophyletic groups (e.g., bootstrapping, Felsenstein, 1985). If we had performed only Dollo or Wagner parsimony of our cpDNA data set we might have come to very different systematic conclusions concerning the number of monophyletic subfamilies in the Asteraceae, as well as relationships among the tribes. The use of both types of parsimony, each of which has some limitations (DeBry and Slade, 1985; Jansen and Palmer, 1988), in conjunction with careful character analysis and bootstrapping permitted us to make more reliable systematic conclusions. Our results clearly emphasize the importance of rigorous phylogenetic analysis of cpDNA restriction site data at higher taxonomic levels.

Second, our study, like those of Sanderson and Donoghue (1989), Archie (1989), and Steele et al. (1991), indicates that the consistency index is not a good indicator of the reliability of phylogenetic estimates. In spite of the low consistency index $(0.44-$ 0.46 , excluding autapomorphies) for the cpDNA data, we were able to make statistically supported statements about phylogenetic relationships. Most of the homoplasy in our data can be attributed to multiple parallel losses in a small proportion of restriction sites (Fig. 6). Because 186 of the restriction sites (166 of which are site gains) only changed once, our data give a very consistent estimate of evolutionary relationships. Deletion of the six most homoplasious characters from the data set had almost no effect on the statistical support for any of the groups in the bootstrap majority-rule consensus tree, although the topology of the most parsimonious tree was affected. Thus, the strongly supported groups are being determined primarily by sites that change only a few times and the very homoplasious sites have little effect on the statistical reliability of the resulting phylogenies. This indicates that the level of homoplasy per se does not determine the reliability of restriction site data in estimating phylogenetic relationships. Rather it is the distribution of homoplasy in the data set. This conclusion may also help explain why Bremer's (1987) phylogenetic analysis of morphological characters in the Asteraceae, which has a substantially higher consistency index (0.65) than our analysis, produced many more equally parsimonious trees (a minimum of 576). Clearly the consistency index alone is not a very accurate indicator of the quality of phylogenetic data. Perhaps the retention index (Farris, 1989a, 1989b) or homoplasy excess ratio (Archie, 1989) will provide a better guide for determining the reliability of phylogenetic data.

\section{ACKNOWLEDGMENTS}

We thank D. Swofford, J. Felsenstein, and S. Farris for providing versions 3.0 of PAUP, 3.2 of PHYLIP, and 1.5 of HENNIG86, respectively, J. Whitton and J. Carpenter for assistance with performing successive approximation, M. J. Spring for assistance with the figures, W. Fink, S. Keeley, R. Olmstead, R. Wallace, and J. Whitton for critical reading of the manuscript, and the University of Connecticut Computer Center for their generosity in allotting 40 hours of CPU time on its IBM 3090. This research has been supported by a grant from the National Science Foundation to J.D.P. and R.K.J. (BSR-8415934).

\section{Literature Cited}

ARCHIE, J. W. 1989. Homoplasy excess ratios: New indices for measuring levels of homoplasy in phylogenetic studies and a critique of the consistency index. Syst. Zool. 38:253-269.

Bremer, K. 1987. Tribal interrelationships of the Asteraceae. Cladistics 3:210-253.

Cabrera, A. L. 1977. Mutisieae-systematic review, pp. 1039-1066. In V. H. Heywood, J. B. Harborne and B. L. Turner (eds.), The Biology and Chemistry of the Compositae. Academic Press, London.

Carlquist, S. 1976. Tribal interrelationships and phylogeny of the Asteraceae. Aliso 8:465-492.

CARPENTER, J. M. 1988. Choosing among multiple equally parsimonious cladograms. Cladistics 4:291296.

DeBry, R. W., AND N. A. Slade. 1985. Cladistic analysis of restriction endonuclease cleavage maps within a maximum-likelihood framework. Syst. Zool. 34:21-34.

FARRIS, J. S. 1969. A successive approximation approach to character weighting. Syst. Zool. 18:374385.

1970. Methods for computing Wagner trees. Syst. Zool. 19:83-92.

—. $1989 a$. The retention index and the rescaled consistency index. Cladistics 5:417-419.

- $1989 \mathrm{~b}$. The retention index and homoplasy excess. Syst. Zool. 38:406-407.

Felsenstein, J. 1973. Maximum-likelihood and minimum-steps methods for estimating evolution- 
ary trees from data on discrete characters. Syst. Zool. 22:240-249.

- 1985. Confidence limits on phylogenies: An approach using the bootstrap. Evolution 39:783791.

. 1988. Phylogenies from molecular sequences: Inference and reliability. Annu. Rev. Gen. 22: 521-565

JANSEN, R. K., AND D. J. PAlmer. 1987a. Chloroplast DNA from lettuce and Barnadesia (Asteraceae): Structure, gene localization, and characterization of a large inversion. Curr. Genet. 11:553-564.

- $1987 b$. A chloroplast DNA inversion marks an ancient evolutionary split in the sunflower family (Asteraceae). Proc. Natl. Acad. Sci., USA 84: 5818-5822.

- 1988. Phylogenetic implications of chloroplast DNA restriction site variation in the Mutisieae (Asteraceae). Am. J. Bot. 75:751-764.

Jansen, R. K., H. J. Michaels, and J. D. Palmer. 1991. Phylogeny and character evolution in the Asteraceae based on chloroplast DNA restriction site mapping. Syst. Bot. In press.

JeFFREY, C. 1978. Compositae, pp. 263-268. In V. H. Heywood (ed.), Flowering Plants of the World. Mayflower Books, N.Y.

LEQUESNE, W. J. 1974. The uniquely evolved character concept and its cladistic application. Syst. Zool. 18:201-205.

Lr, W.-H. 1986. Evolutionary change of restriction cleavage sites and phylogenetic inference. Genetics 113:187-213.

Moritz, C., T. E. Dowling, AND W. M. Brown. 1987. Evolution of mitochondrial DNA: Relevance for population biology and systematics. Annu. Rev. Ecol. Syst. 18:269-292.

NeI, M., AND F. TAJima. 1985. Evolutionary change of restriction cleavage sites and phylogenetic inference for man and apes. Mol. Biol. Evol. 2:66-85.

-1987. Problems arising in phylogenetic inference from restriction-site data. Mol. Biol. Evol. 4:320-323.

PALMER, J. D. 1985. Comparative organization of chloroplast genomes. Annu. Rev. Genet. 19:325354.

- 1986. Isolation and structural analysis of chloroplast DNA. Meth. Enzymol. 118:167-186.

- 1987. Chloroplast DNA evolution and biosystematic uses of chloroplast DNA variation. Am. Nat. 130:S6-S29.

Palmer, J. D., R. K. Jansen, H. J. Michaels, M. W. Chase, and J. R. Manhart. 1988. Chloroplast DNA variation and plant phylogeny. Ann. MO Bot. Gard. 75:1180-1206.
Saghai-Maroof, M. A., K. M. Soliman, R. A. JorGENSEN, AND R. W. Allard. 1984. Ribosomal DNA spacer length polymorphisms in barley: Mendelian inheritance, chromosomal location, and population dynamics. Proc. Natl. Acad. Sci., USA 81:8014-8018.

SANDERSON, M. J. 1989. Confidence limits on phylogenies: The bootstrap revisited. Cladistics 5:113129.

SAnderson, M. J., AND M. J. Donoghue. 1989. Patterns of variation in levels of homoplasy. Evolution 43:1781-1795.

SChIlling, E. E., AND R. K. JANSEN. 1989. Restriction fragment analysis of chloroplast DNA and the systematics of Viguiera and related genera (Asteraceae: Heliantheae). Am. J. Bot. 76:1771-1780.

Steele, K. P., K. E. Holsinger, R. K. Jansen, and D. W. TAYLOR. 1991. Assessing the reliability of 5S rRNA sequence data for phylogenetic analysis in green plants. Mol. Biol. Evol. In press.

Sytsma, K. J., AND B. A. SchaAl. 1985. Phylogenetics of the Lisianthius skinneri (Gentianaceae) species complex in Panama using DNA restriction fragment analysis. Evolution 39:594-608.

Sytsma, K. J., AND L. D. GotTlieb. 1986. Chloroplast DNA evolution and phylogenetic relationships in Clarkia sect. Peripetasma (Onagraceae). Evolution 40:1248-1262.

Templeton, A. R. 1983a. Phylogenetic inference from restriction endonuclease cleavage site maps with particular reference to the evolution of humans and apes. Evolution 37:221-244.

. 1983b. Convergent evolution and non-parametric inferences from restriction fragment and DNA sequence data, pp. 151-179. In B. S. Weir (ed.), Statistical analysis of DNA sequence data. Marcel Dekker, N.Y.

1987. Nonparametric phylogenetic inference from restriction cleavage sites. Mol. Biol. Evol. 4: 315-319.

ThORNe, R. 1983. Proposed new realignments in the angiosperms. Nord. J. Bot. 3:85-1 17.

WAGENITZ, G. 1976. Systematics and phylogeny of the Compositae (Asteraceae). Pl. Syst. Evol. 125: 29-46.

WALlACE, R. S., AND R. K. JANSEN. 1990. Systematic and evolutionary implications of chloroplast DNA variation in Microseris (Asteraceae: Lactuceae). Syst. Bot. 15:606-616

Corresponding Editor: M. J. Donoghue 


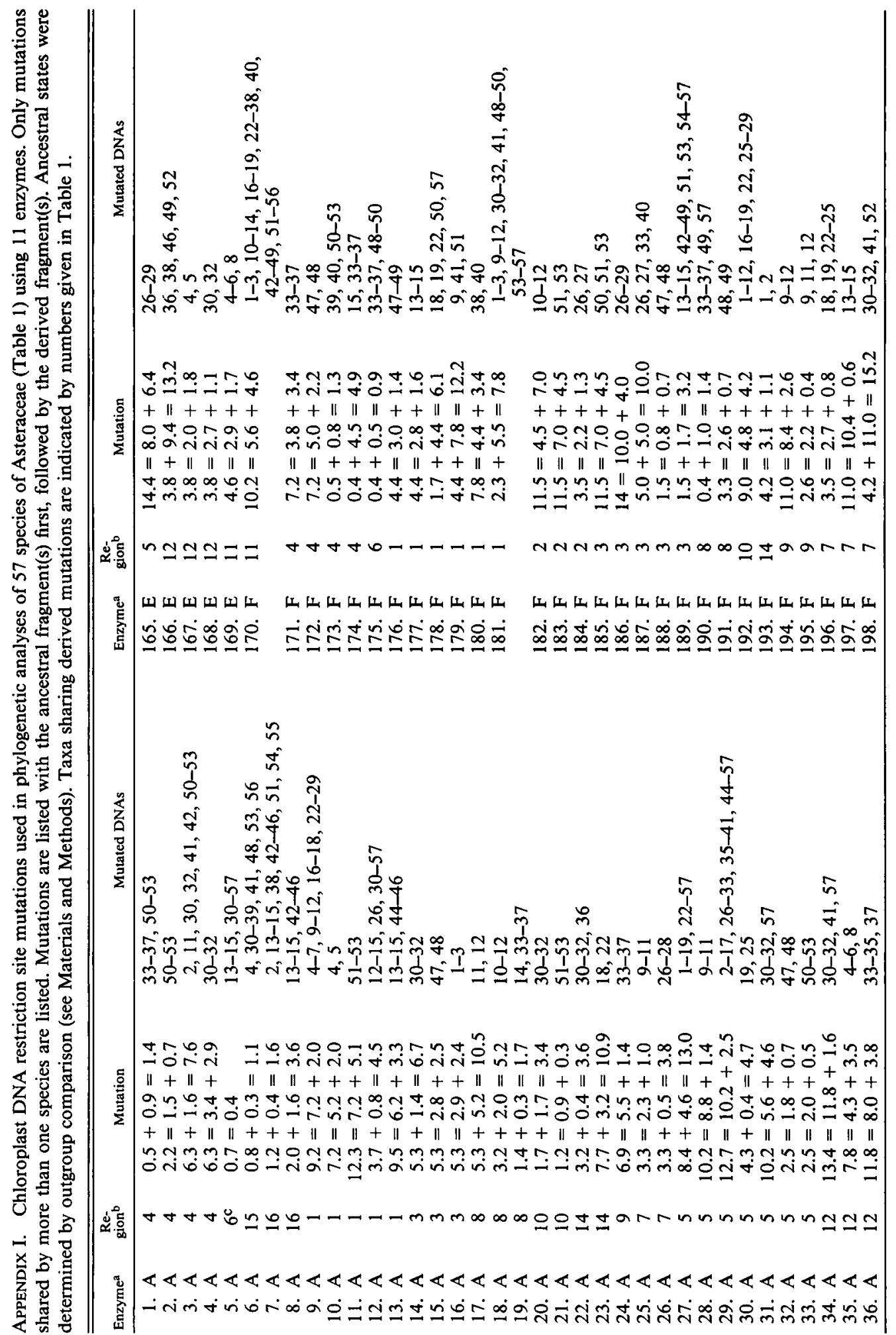




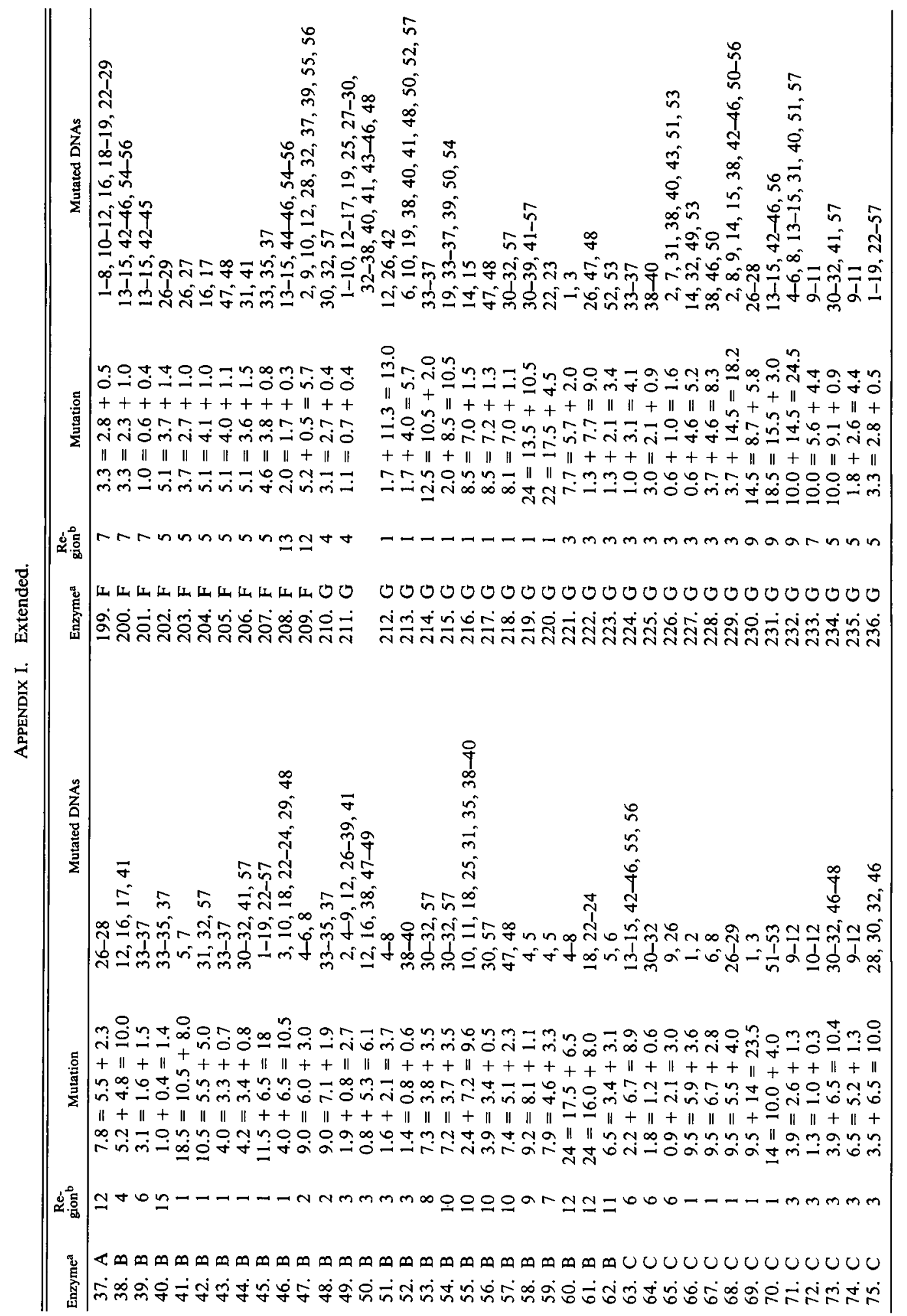




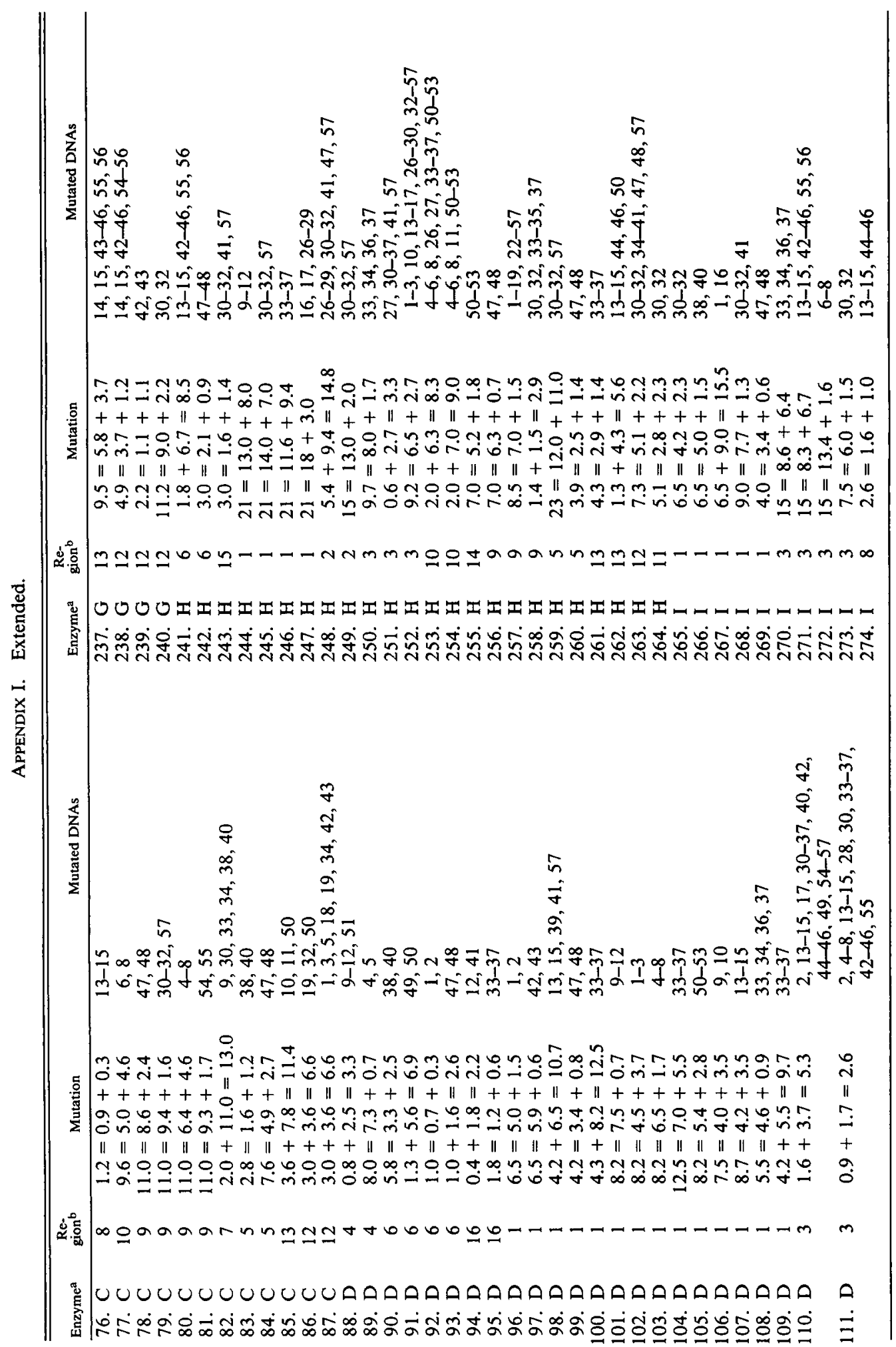




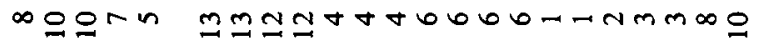

mัँ $\|+\| n+++\|\|\|++++++\| \|$

m ก๊mm

तin

$+\|++\|\|\|+++\|\|\|\|\|\|++$

이웅 무요

तiñ

$\frac{n}{n}$

m

$\curvearrowleft \tilde{m}$

in n

in

กิ

茫

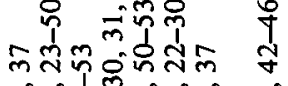

in $\frac{0}{1}$

م

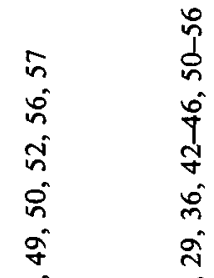

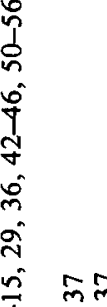

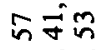

$i m$

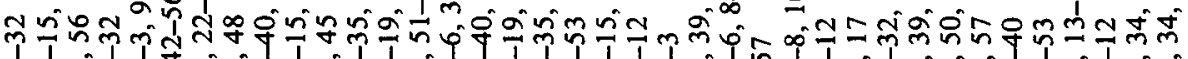

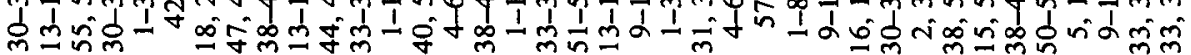

mmon?

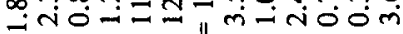
++++\|\| lo $t+\|+++$ nnownrmonrab ஸैं ป \|\|$\|+++\|\|+\|\|\|$

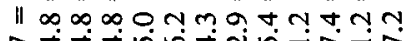

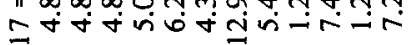

orrRーMำ

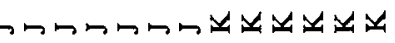

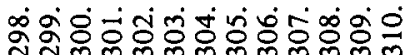

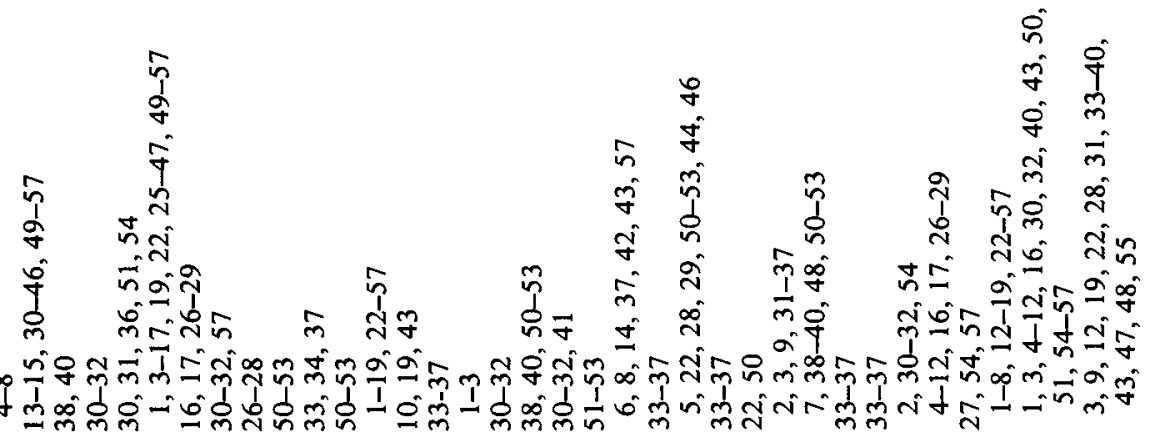

rmtrogontnmonntommbootoonshbma?tann

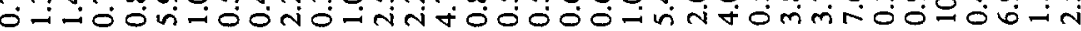
$t+t++\|t+t\|+++\|\|++t+++\|+\|+\|\|\|+\|\|+\|+\|$

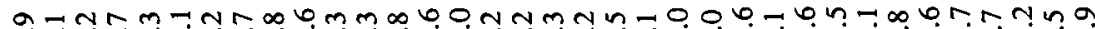

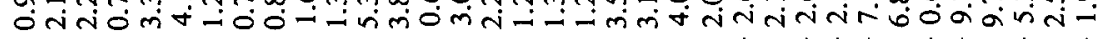
\|\|\|\|$+\|\|\|+\|\|\|++\|\|\|\|\|\|+\|+\|+++\|++\|+\|+$

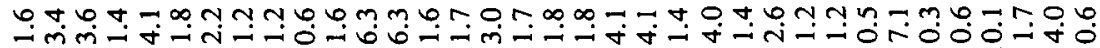

mmmmmm 


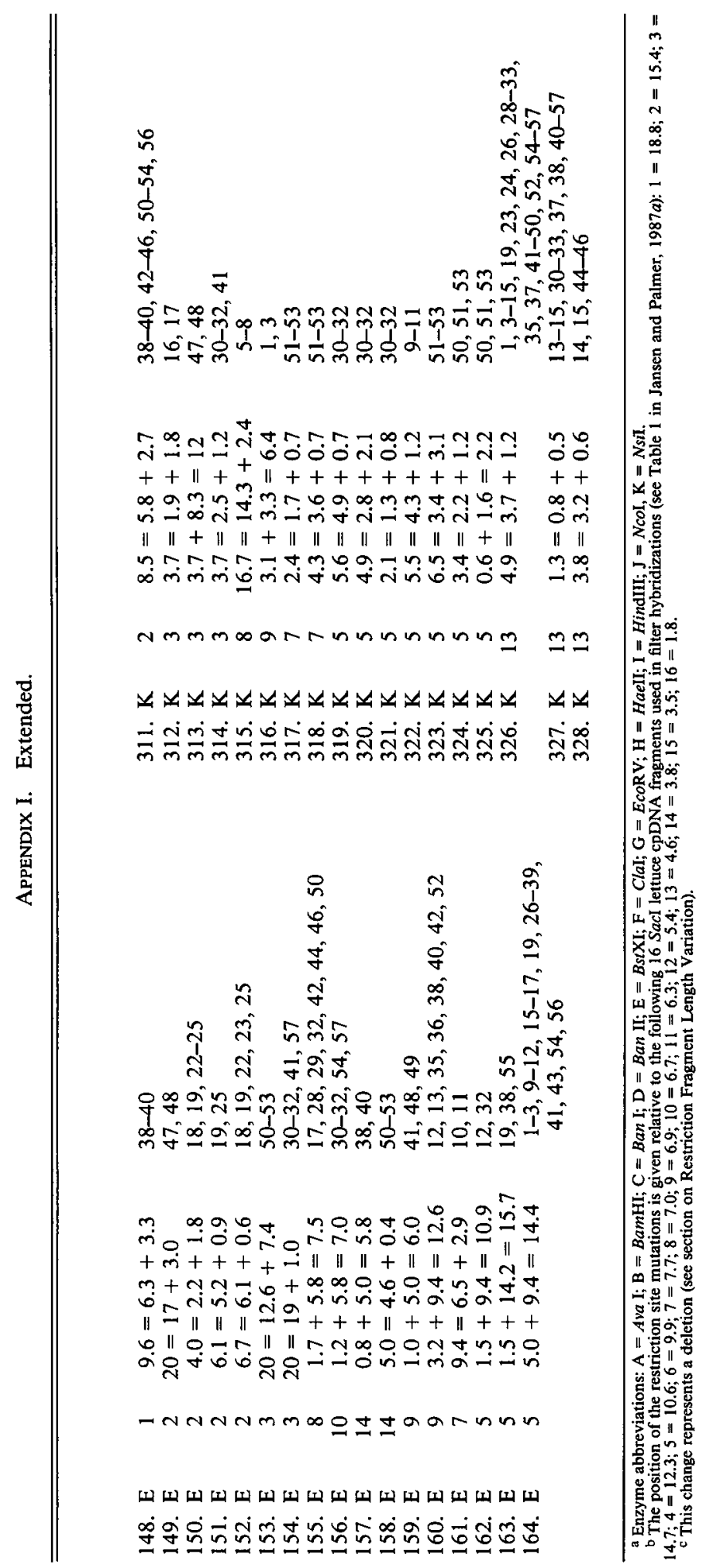




\section{APPENDIX II}

Felsenstein (1973) has shown that the maximum likelihood estimate of a phylogeny corresponds to the Wagner parsimony estimate when the rate of change for any particular character is small and the rates of change for all characters are approximately equal. We seek a method of detecting characters that are changing more rapidly than is consistent with the hypothesis that all characters in the sample are changing at equal rates.

We start with a Wagner parsimony estimate of phylogenetic relationships. Notice that if all characters in the sample are changing at equal rates, then the number of changes each character has undergone will be equal, within the limits of statistical error. If there are a total of $B$ branches and the number of changes observed for character $\mathrm{i}$ is $n_{i}$, then the proportion of branches on which i changes is simply $p_{\mathrm{i}}=n_{\mathrm{i}} / B$. We develop a conservative test for the null hypothesis that all of the $p_{\mathrm{i}}$ are equal.

Under the null hypothesis that all characters are changing at equal rates, the maximum likelihood estimate of $p$, the proportion of branches on which a character changes, is simply $p=(1 / N) \Sigma p_{\mathrm{i}}$, where $N$ is the total number of characters. Let $\pi(k)$ be the probability that a given character changes $k$ or fewer times. Then

$$
\pi(k)=\sum_{n=1}^{k} C(B, n) p^{n}(1-p)^{\mathbf{B}-n} ;
$$

where $C(B, n)$ is the binomial coefficient. Let $1-\alpha(k)$ be the probability that all of the characters change $k$ or fewer times. Then $1-\alpha(k)=\{\pi(k)\}^{N}$. Thus, $\alpha(k)$ $=1-\{\pi(k)\}^{\mathrm{N}}$ is the experimentwise probability that at least one character changes $k$ or more times.

Let $\alpha$ be the experimentwise probability that we seek. Then we seek the largest $k$ such that $\alpha \leq \alpha(k)$. This is equivalent to finding the largest $k$ such that

$$
\{\pi(k)\}^{N} \leq 1-\alpha .
$$

Given $\alpha$ and the estimate of $p$ obtained above, it is a simple matter to evaluate $\pi(k)$ and determine the largest $k$ for which (Al) is satisfied. The experimentwise probability of observing any characters that change more than $k$ times is less than or equal to $\alpha$. Thus, all characters that change more than $k$ times are statistical outliers that should be removed from the analysis.

Note added in proof: We have recently analyzed the restriction site data by using the step matrix in PAUP $3.0 \mathrm{k}$. Gains were weighted over losses by a factor of 1.3 as recommended by V. Albert, B. Mishlev, and M. Chase (unpubl.). A single tree was produced that had the Dollo topology (Figs. 3, 5) with both the subfamilies Asteroideae and Lactucoideae monophyletic. 